 \\ doi:10.20396/revpibic262018760
}

XXVI Congresso de Iniciação Cientifica Unicamp.

8.

\section{Análise acerca das relações profissionais entre as diferentes áreas de atuação no consultório de rua de rua}

\author{
Kátia de Freitas Santos, Sérgio Rezende de Carvalho, Cathana Freitas de Oliveira.
}

Resumo: O presente projeto teve por finalidade apresentar os aspectos gerais da população em situação de rua (PSR) e do Consultório na Rua (CnaR). Verifica-se que o CnaRua é uma importante alternativa ao acesso à saúde para a PSR, mostrando também que o atendimento é realizado buscando entender a atuação e a importância de cada profissional em exercício complementar interprofissional de equipe. Assim, essa pesquisa visa por meio de visitas e entrevistas, entender melhor a atuação de cada profissional para que assim seja possível propor melhorias na equipe, direcionadas às necessidades da PSR, tendo em vista que devido às suas singularidades, a PSR por vezes não consegue acesso às redes tradicionais de saúde.

Palavras-chave: População em Situação de Rua, Atenção Básica, Redução de danos.

\section{Introdução}

O problema do acesso da PSR aos serviços da rede assistencial é bastante relevante. Como resposta a essa demanda, o CnaR é importante opção com a finalidade de ampliar o acesso à saúde para este grupo social tão marginalizado.

\section{Objetivos Gerais:}

Analisar as relações entre as diferentes áreas de atuação profissional em exercício no consultório de rua.

\section{Objetivos Específicos:}

A importância do trabalho em equipe.

O papel de cada profissional na equipe de CnaR.

O papel de cada profissional no exercício da redução de danos na PSR.

\section{Resultados e Discussão}

Análise geral do funcionamento do CnaR: Visitas foram o intercâmbio para se observar o funcionamento do trabalho em equipe entre os profissionais do CnaR. Foi possível ter uma ideia geral do trabalho desenvolvido pelos profissionais no CnaR com a análise de uma pessoa que não é nem usuário nem profissional do CnaR.

Entrevista com usuários do CnaR: Entrevistas realizadas com diferentes grupos para avaliar como eles são tratados pelo conjunto de profissionais da equipe $e$ como cada um realiza a sua função individualmente e coletivamente. As pessoas selecionadas para a entrevista eram em situação de rua e usuários do CnaR..

Entrevista com profissionais do CnaR: Entrevistas realizadas com profissionais de diferentes áreas atuante no CnaR (médico, enfermeiro, psicólogo, redutor de danos) para avaliar como é desenvolvido o seu papel individualmente e coletivamente no CnaR.

Figura 1. Parte da equipe multiprofissional atuante no CnaR de Campinas.

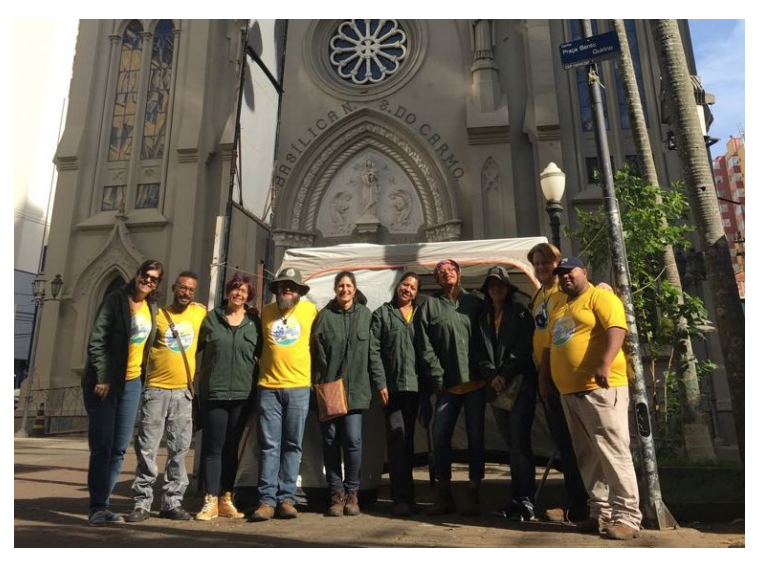

\section{Conclusões}

O trabalho da equipe é nômade, acompanhando o movimento e as necessidades de quem vive na rua e busca prestar uma atenção integral à saúde da PSR em compartilhamento com as unidades básicas e buscando formação de rede intersetorial. Estratégias como a redução de danos e a criação de vínculo com utilização de diferentes dispositivos, como a música, utilizados no CnaR, aumentam a adesão ao tratamento e promoção de autocuidados.

\section{Agradecimentos}

Agradeço à Unicamp, à $\mathrm{CNPq}$, ao meu orientador Sérgio Rezende de Carvalho, à sua doutoranda Cathana Freitas de Oliveira e à minha família.

Brasil. Ministério da Saúde. Secretaria de Atenção à Saúde. Departamento de Atenção Básica. Manual sobre o Cuidado à Saúde junto a População em Situação de Rua. Brasília: Ministério da Saúde; 2012. p. 17-18 / p. 13. Carneiro Junior N, Jesus CH de, Crevelim MA. A Estratégia Saúde da Família para a equidade de acesso dirigida à população em situação de rua em grandes centros urbanos. Saúde e Soc [Internet]. 2010 Jan 29];19(3):709-16. Mariani de Souza Azevedo, Bruno . A Aposta no encontro para a produção de redes de saúde. 2016. 183 f. Tese de doutorado (Doutorado em saúde coletiva) - Faculdade de Ciências Médicas, UNICAMP, Campinas, SP, 2016. p 77/78. Tedesco, Silvia; De Paula Souza, Tadeu . Territórios da Clínica: Redução de Danos e o Novos Percursos Éticos Para a Clínica das Drogas. Trabalho acadêmico. p142 a 156 